\section{New York besieged: 11 September and after}

E pidemiologists all over the world have been good enough to express their concerns and worries about how we, and other friends and colleagues in New York, fared in the terror provoked on 11 September. This annotation responds to the editors' invitation that we convey something from our vantage point. We welcomed their interest. The experience is, so far, unique in history. Our account is personal, that of four individuals, all related (Sally married to Ezra, and Ezra born to Mervyn and Zena). We share the same house. Also, atypically for any institution, all are of the Department of Epidemiology in the Mailman School of Public Health of Columbia University.

The themes we emphasise are common to many others among us in New York City. On the day of 11 September and after, much of what we saw and heard was televised, a source open to everyone else here and elsewhere. In some degree, then, much of the world was exposed to the New York experience. But in the Department of Epidemiology (the School and the Medical Center are on the north west outskirts of Manhattan) we were not only in propinquity to the events, we looked directly upon them from the south facing windows of the 18th floor of our own dwarfed tower.

On the day of 11 September, only Sally and Ezra were in the city. Zena and Mervyn were in South Africa. We tell the story as it unfolded in both situations. In New York, immediately the first plane hit the South Tower of the World Trade Center, many of us, alerted to what seemed a tragic accident, went to our south looking windows. From there, horrified, we watched a second plane enter our view, veer toward and then disappear into the North Tower, becoming instantly enveloped, together with the upper levels of the tower, in a vast sheet of flame. At once, all understood the "accident" to be what it was-unimaginable evil. It was clear that twenty to thirty thousand people working in the Towers every day could be at risk, not counting even larger numbers visiting on business.

In shock or fright, first thoughts for many of us revolved around the fate of the friends or relatives whose work brought them there, and that of the children we knew to be in schools nearby. In the Medical Center, Ezra and many senior faculty and staff of the School of Public Health and all the other schools of the Health Sciences Faculty stood by for action, planning emergency care. They were not yet aware that from the Towers no route was open by which the casualties could reach the Medical Center. Nor could they yet know that in any case surviving casualties would be relatively few. Most were dead and turned to ash, obliterated by the 1500 degree (centigrade) flames ignited by exploded plane tanks filled with petroleum.

For the rest of us, thoughts about what a relief effort would require and about what our contributions might be were frustrated. Many like ourselves live outside Manhattan. We were told to get home and not place any unnecessary burden on the limited transport, food and relief supplies within the island. Yet little could go either in or out. Bridges and roads and subways were shut down, especially in Mid and South Manhattan.

When by late evening most of us did get home, we sat numbly through the hours of replays. Unforgettable moments are seared into memory. The succession of events and images insistently deepened horror and pain: first impact and explosion; then the collapse of the towers; then scared people fleeing a tsunami-like cloud of pulverised concrete and steel and charging on foot up the West Side Highway, their eyes on the lookout and turned to the sky.

We blanched as the battalion of firemen rushed into and up the burning tower. Some of them must have been well aware of the imminent collapse of the towers and their own probable annihilation. Few returned. Other moments were empathetic projections of grief: we saw families leaving the Los Angeles airport on learning their children had boarded one of the three planes transmuted into death-dealing missiles. Survivors, witnesses and rescue teams recounted what ordinarily would have been merely our worst nightmares.

The seeming safety of life in the United States-neither invaded nor terrorised in the 20th century-vanished in an instant. Like some other countries, we now are shadowed by the grief of a terrorist attack and by the expectation and fear of terrorist attacks to come. But on such a scale! Were symbols of business, government and the military always to be targets-the more civilians killed the better-and airliners the lunatic weapons of mass destruction?
In the days after the strike, it often seemed that the destruction could not have been real. But each day our office windows framed the reality, the familiar towering landmark missing, and each evening the television screen replayed footage of those minutes of destruction as the second plane sliced into the middle of the North Tower. Periodically, we found tears could not be stanched in the face of recurring images: people hurling themselves out of the upper windows to escape the flames, their bodies falling and twisting like fragile kites and autumn leaves; and 50 floors, filled with people still very much alive, engulfed in flame. In one piece of footage, intact towers held people who chatted to each other, walked from one room to another, unsuspecting... people now crushed beneath piles of steel girders and concrete, no relic left but simply part of the rubble.

Slowly, as we began to hear from acquaintances throughout the region, we realised just how many people had offices in or near the World Trade Center. The vast numbers quoted by reporters were anonymous [In an effort to give all the victims an identity, the New York Times publishes each day a full page of photographs with details about victims. The intent is to report on all who can be traced, a memorial cross section of a great city]. But almost everyone had some kind of personal encounter that made the event the more devastating. Our children told of happenings in the schools: a student whose father worked at the World Trade Center; hysterical at the news of its destruction the principal brought to the classrooms; a teacher, whose wife worked at the Center, on hearing the news, rushing straight out of the room in the middle of class. The man who delivers our newspaper, having lost his brother in law, was left worrying how he could fend for his sister and her four children.

Others were kept away from work in the Towers for various mundane reasons. One child cried all day before she learned that a doctor's appointment had kept her mother away and safe. One friend, a little late that morning and waiting for the elevator when the first plane struck, ran out and escaped the destruction. But many we know lived in the neighbourhood of the World Trade Center and had to vacate their apartments and lodge wherever they could. Our teenage children were visibly distressed and anxious. At the School of Public Health and the Department of Psychiatry, faculty gave time and solace to those bereaved and in shock.

Meanwhile, we (Zena and Mervyn) were still in Johannesburg, lingering with old friends at the tail end of an expedition to promote research and training in face of the emergent devastation of HIV/AIDS and resurgent tuberculosis. Due to leave for New York on Wednesday 12 September, we and thousands of others were forestalled by the destruction of Tuesday 11 September.

It happened on that Tuesday afternoon (the time six hours ahead of New York), as we returned to the home of their Johannesburg friends, the housekeeper had the television turned on. Within a moment, they were faced with the unbelievable images of the second airliner exploding into the North Tower. Soon we learned that all New York airports were closed and all flights were cancelled. Benumbed, bemused and fragile in spirit, we spent four days travelling from the city to the airport in a daily struggle at the booking desk to obtain a passage, and obsessively watching the mesmerising television images and reportage. For some desperate hours, we tried to circumvent the constant thwarting of our every attempt to speak by telephone to the members of the families of our three offspring in the USA. We were at last rewarded by the news that they at least were all safe.

Still, we mourned the destruction. As the decades of our exiled lives had passed, we had grown to love the great city of New York for its rich intellectual and artistic life and its energy, diversity, and warmth. Among our friends of all races in Johannesburg, however, we relearned what we might have recalled from their own now ancient histories in radical opposition there: not all in South Africa would be empathetic or even sympathetic with the plight of New York City and the devastation brought upon imperial might.

Soon, however, Zena and Mervyn were back in New York and together we slowly restructured our perspectives on life and work. We all soon grasped that this malign and orchestrated tragedy opened a new chapter in history-and in epidemiology. We began the business of facing and contending with that knowledge. In fact, we were soon immersed in the ensuing events. 
Almost immediately we needed to come to terms with what we hoped was the metaphorical war on terrorism declared by the untried president. In grappling with the threat of chemical and bioterrorism, a central role falls naturally to the Department of Epidemiology in the School of Public Health. Weeks later, with bioterrorism upon us in the form of anthrax, we know for certain that the threat was no illusion. Our department-strong in psychiatric epidemiology-is also immersed in dealing with the impact of terror on the mental health of the affected population and preparing for mental health consequences of future attacks. At the same time, we believe it equally important, and perhaps even more daunting, for us to keep attention, our own and that of others, on the other great and persisting public health problems of today's world and, in particular, the catastrophe of HIV/AIDS in Africa.
Will this tragedy have any lasting impact on the discipline of epidemiology? We believe it will. The public has called epidemiologists into action and they are necessarily on centre stage in these epic events. It is a call that cannot be ignored. We believe that the notion of separating epidemiology from public health action-popular in the USA in recent years-has collapsed along with the World Trade Center.

Sally Conover, Zena Stein, Ezra Susser, Mervyn Susser Dept of Epidemiology Columbia University

New York, USA

Correspondence to: ProfE Susser; ess8@columbia.edu

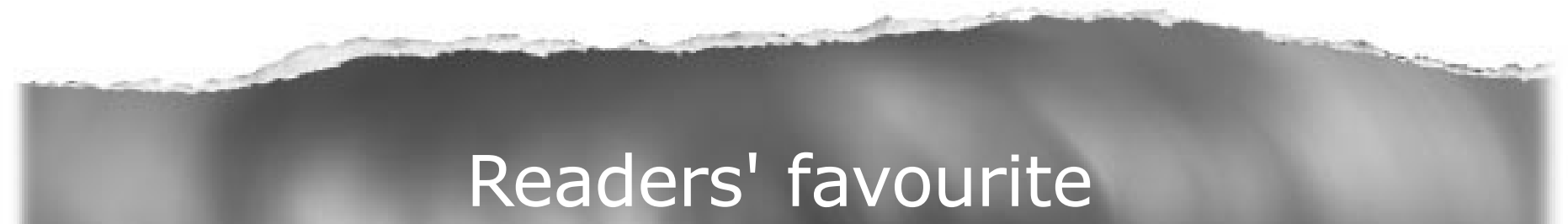

Top 10

Click on the "Top 10" button on the homepage to see which are the best read articles each month

\section{www.jech.com}

